\title{
Investigation of the Transition Reaction of Tobermorite to Xonotlite under Influence of Additives
}

\author{
Andrea Hartmann, David Schulenberg, Josef-Christian Buhl \\ Institute of Mineralogy, Hannover University, Hannover, Germany \\ Email: a.hartmann@mineralogie.uni-hannover.de
}

Received 10 March 2015; accepted 12 April 2015; published 16 April 2015

Copyright ( 2015 by authors and Scientific Research Publishing Inc.

This work is licensed under the Creative Commons Attribution International License (CC BY). http://creativecommons.org/licenses/by/4.0/

(c) (1) 0pen Access

\section{Abstract}

The objective of the present work was to investigate the transition reaction of the calcium silicate hydrate tobermorite into xonotlite under influence of additives. Tobermorite is the main binding agent in steam hardened building materials and the appearance of xonotlite indicates the progress of hardening and an overcuring of the material. Hydrothermal experiments under addition of sucrose, calcium formate and calcium chloride dihydrate to the main components quartz and lime were done using temperatures of $220^{\circ} \mathrm{C}$ and a reaction time of $40.5 \mathrm{~h}$. All experiments were performed with powders as well as with pressed educts. The products of all syntheses were analyzed with XRD, SEM/EDX and FTIR. The references as well as the syntheses with calcium chloride dihydrate led to the formation of $11 \AA$ tobermorite and xonotlite. The former showed the best results and even synthesis with pressed educts and calcium chloride dihydrate revealed an accelerating effect of the additive. In contrast syntheses with sucrose had the worst reactivity and led to the formation of calcite beside the CSH-phase scawtite. The additive calcium formate was only slightly oppressing the crystallization of tobermorite and favouring the formation of xonotlite. Syntheses with pressed pellets and sucrose or calcium formate showed generally worse results.

\section{Keywords}

CSH-Phases, Tobermorite, Xonotlite, Additives, Retarder, Accelerator

\section{Introduction}

Additives play an important role in the production of building materials. Their accelerating or retarding effects on the course of hydraulic reactions are widely used in concrete production and cement treatment to comply the 
requirements of the material [1]-[5]. Basic research in building materials chemistry over decades could reveal many facets of the reaction modifications under influence of organic and inorganic additives. Retarding processes based on specific adsorption of ions of the additive on the surface of the growing phases like tricalcium silicate $\left(\mathrm{C}_{3} \mathrm{~S}\right.$; $\left.\mathrm{C}: \mathrm{CaO}, \mathrm{S}: \mathrm{SiO}_{2}\right)$ in cement was observed for classical retarders like sucrose. Rapid growth of $\mathrm{C}_{3} \mathrm{~S}$ is thus inhibited [6]. As this process is strongly connected with consumption of calcium-ions, the C/S ratio in the system diminishes resulting in further retarding of the progress of setting and hardening of cement [7]-[9].

In accelerators like calcium chloride the ionic potential of cations and anions contribute to the effect by influencing the ion-hydratation processes as well as the diffusion and the transport of building blocks from the solution to the growing crystals [10]-[12]. Similar effects were observed with organic accelerators like calcium formate [1] [13]. Even the simple role of decrease of $\mathrm{pH}$-value has to be taken into account when additives are inserted [14]-[16]. In contrast, an increase of alkalinity was found to have no remarkable effect on $\mathrm{C}_{3} \mathrm{~S}$ hydratation [13] [17].

Compared with the comprehensive theoretical studies and experimental work connected with cement and concrete investigations on insertion of additives in the field of steam hardened building materials are much lesser numerous. Those materials were produced by autoclave curing at $160^{\circ} \mathrm{C}-200^{\circ} \mathrm{C}$ under saturated steam pressure from quartz, burnt lime and water. Calcium-silicate-hydrate phases (CSH-phases) were formed during this reaction within a few hours [18]-[20]. The main important phase, obtained during steam curing around $180^{\circ} \mathrm{C}$ is the CSH phase $11 \AA$ tobermorite. The proper crystallization of this chain silicate with needle to band-like morphology is essential for a sufficient firmness of the material, as tobermorite is the main binding agent in steam hardened building materials. Tobermorite belongs to the group of chain silicates and its structure and real structure is well known [21]-[23]. The tobermorite formula depends on slight deviations in chemical composition according to differences of water molecules and hydroxyl groups per unit-cell. The compositions $\mathrm{Ca}_{5} \mathrm{Si}_{6} \mathrm{O}_{17} \times$ $5 \mathrm{H}_{2} \mathrm{O}\left(\mathrm{C}_{5} \mathrm{~S}_{6} \mathrm{H}_{5} ; \mathrm{H}: \mathrm{H}_{2} \mathrm{O}\right)$ [20] and $\mathrm{Ca}_{5}\left[\mathrm{Si}_{6} \mathrm{O}_{16}(\mathrm{OH})_{2}\right] \times 2 \mathrm{H}_{2} \mathrm{O}$ [21] were usually used for tobermorite with the $\mathrm{CaO} / \mathrm{SiO}_{2}$-ratio $(\mathrm{C} / \mathrm{S})$ of 0.83 . The crystallization process of tobermorite starts with formation of calcium rich so-called pre-phases like CSHI and $\alpha-\mathrm{C}_{2} \mathrm{SH}$ followed by $11 \AA$ tobermorite. The latter transforms into xonotlite $\mathrm{C}_{6} \mathrm{~S}_{6} \mathrm{O}_{17}(\mathrm{OH})_{2}$ at prolonged reaction time and elevated temperatures $220^{\circ} \mathrm{C}$ [18]-[20] [24]. As mentioned above there is only a few knowledge on the effects of additives during this formation of CSH-phases in steam hardened building materials like lime sand stones and autoclaved aerated concrete. In our former experimental study the addition of sucrose [25], calcium formate [26] and calcium chloride dehydrate [27] during tobermorite synthesis was investigated at $200^{\circ} \mathrm{C}$ and autogeneous pressure. A retarding effect of sucrose on the tobermorite crystallization was observed. The additive calcium formate indicates only a slightly retarding effect of tobermorite crystallization. However syntheses with addition of calcium chloride dihydrate resulted in an accelerating effect on the tobermorite crystallization.

In the present paper the influence of the additives sucrose, calcium formate and calcium chloride dihydrate on the transition reaction of tobermorite to xonotlite $\mathrm{Ca}_{6} \mathrm{Si}_{6} \mathrm{O}_{17}(\mathrm{OH})_{2}\left(\mathrm{C}_{6} \mathrm{~S}_{6} \mathrm{H}\right)$ was investigated in dependence of different mass ratios of the additive beside lime and quartz. This selected reaction is of special interest in production of steam hardened building materials as the occurrence of noticeable parts xonotlite beside tobermorite indicates the start of over curing of the material.

\section{Experimental}

\subsection{Syntheses}

In the present paper two synthesis series were done-series a) with powder educts and b) with pressed educts. For both types first reference syntheses without additives were prepared. As in former experiments on CSH crystallization [25]-[28] for all syntheses with powders $1.5 \mathrm{~g}$ fine grained quartz with particle size $>230$ mesh (FLUKA 83340) was selected as silica source. Lime was obtained by calcination of $\mathrm{CaCO}_{3}$ (Johnson Mattay $\mathrm{GmbH}$ ) at $1000^{\circ} \mathrm{C}$ for $3 \mathrm{~h}$ and amounts of $1.16 \mathrm{~g}$ (for reference syntheses) or $0.75 \mathrm{~g}$ for experiments with the additives were used. For additives amounts of $1.16 \mathrm{~g}$ sucrose $\mathrm{C}_{12} \mathrm{H}_{22} \mathrm{O}_{11}$ (Aldrich S5016-500G), $0.85 \mathrm{~g}$ calcium formate $\mathrm{C}_{2} \mathrm{H}_{2} \mathrm{CaO}_{4}$ (Sigma 21,134) or 0.96 g calcium chloride dihydrate $\mathrm{CaCl}_{2} \times 2 \mathrm{H}_{2} \mathrm{O}$ (Merck 2380) were inserted. The sample numbers and the $\mathrm{CaO} / \mathrm{SiO}_{2}$ ratios of the experiments are summarized in Table 1 . The individual mass ratios were selected to obtain a $\mathrm{C} / \mathrm{S}$ ratio of 0.8 for the references and the experiments with calcium formate and calcium chloride dihydrate. In contrast, for the insertion of sucrose a lower $\mathrm{C} / \mathrm{S}$ ratio of 0.5 resulted 
Table 1. Sample numbers and $\mathrm{CaO} / \mathrm{SiO}_{2}$ ratios $(\mathrm{C} / \mathrm{S})$ of the batches.

\begin{tabular}{ccc}
\hline Sample $^{*}$ & Additive & C/S \\
\hline $1 \mathrm{a}+\mathrm{b}$ & - & 0.8 \\
$2 \mathrm{a}+\mathrm{b}$ & Sucrose & 0.5 \\
$3 \mathrm{a}+\mathrm{b}$ & Calcium formate & 0.8 \\
$4 \mathrm{a}+\mathrm{b}$ & Calcium chloride dihydrate & 0.8 \\
\hline
\end{tabular}

*a: synthesis with powder, b: synthesis with pellet.

as it was our aim, to insert a constant amount of $0.75 \mathrm{~g}$ of reactive lime $\mathrm{CaO}$ in each of the three experiments with additives. For series a) the powdery educts were filled into $50 \mathrm{ml}$ steel autoclaves with Teflon liners and 20 $\mathrm{ml}$ distilled water was added. For the syntheses with pellets (series b) in each case only half of the educt masses as inserted for powders were used and first pressed under a hydraulic press with special mold at 5 t for 5' into 4 $\mathrm{mm}$ thick tablets of $12 \mathrm{~mm}$ diameter, before placed in a special Teflon sieve inlay inside each autoclave. Again $20 \mathrm{ml}$ water was filled in the liners. The autoclaves were heated in an oven at $220^{\circ} \mathrm{C}$ for $40.5 \mathrm{~h}$. After this reaction time the products were filtered, washed with water and dried at $80^{\circ} \mathrm{C}$ for $24 \mathrm{~h}$.

\subsection{Analytical Methods}

The synthesis products were analyzed by XRD, SEM/EDX and FTIR spectroscopy. X-ray powder data were collected on a Bruker Endeavour D4 powder diffractometer (Bragg-Brentano geometry) using Ni-filtered CuK $\alpha$ radiation at $40 \mathrm{kV}$ and $40 \mathrm{~mA}$. The measurements were performed with a step width of $0.03^{\circ}$ in the range of $5^{\circ}$ $85^{\circ} 2$ Theta. 2668 steps of $1 \mathrm{~s}$ duration were measured. The data were analyzed using the WinXPow software of Stoe \& Chi.

Beside these measurements for an overview on the qualitative course of syntheses, selected products of series (a) were analysed quantitatively by Rietveld refinement of X-ray powder data. Therefore a high quality pattern was measured in the range of $2^{\circ}-80^{\circ} 2 \theta$ with $0.01^{\circ}$ step wide and $10 \mathrm{~s}$ of measurement of each step. The Topas 4.2 software (Bruker AXS) was used for data evaluation.

The morphology and chemical composition of the synthesis products were analyzed on a Jeol JSM-6390A scanning electron microscope (SEM) at an accelerating voltage of $20 \mathrm{kV}$ or $30 \mathrm{kV}$. The SEM was coupled with a Bruker QUANTAX EDX Spektrometer equipped with the XFlash M410 EDX detector. The samples therefore were sputtered with a fine layer of gold to prevent electric charging during measurement. A signal of gold (Au) therefore exists in each EDX spectrum. Infrared spectra were taken on a Bruker IFS66v FTIR spectrometer. The samples therefore were diluted by $\mathrm{KBr}$ (about $1 \mathrm{mg}$ sample in $200 \mathrm{mg} \mathrm{KBr}$ ), pressed into pellets and measured relatively to the $\mathrm{KBr}$ as a reference.

\section{Results}

\subsection{XRD and SEM/EDX Analysis}

\subsubsection{The Products of Reference Syntheses without Additives}

From the XRD powder patterns of reference syntheses products with quartz powder (Figure 1(a)) a high amount

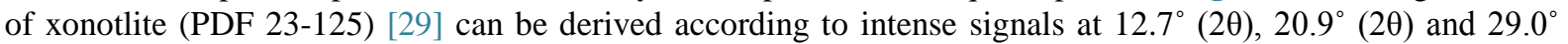

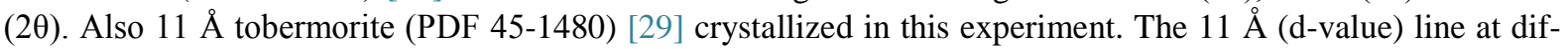
fraction angle $7.8^{\circ}(2 \theta)$ appears and also signals at $29.0^{\circ}(2 \theta)$ und $32.0^{\circ}(2 \theta)$. The XRD analysis also shows quartz (PDF 46-1045) [29] with signals at $20.9^{\circ}(2 \theta)$ and $26.6^{\circ}(2 \theta)$. The powder pattern of synthesis products

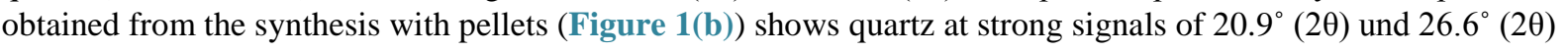
beside weak ones of xonotlite and tobermorite.

A quantitative evaluation by Rietveld method is given in Table 2 for the experiment with powder.

Xonotlite as main phase beside a small amount of tobermorite was detected by Rietveld analysis (Table 2). Quartz was observed only on very low scale. Table 2 also includes the amounts of the CSH-phases after subtraction of the quartz fraction.

Figure 2 shows a SEM image of the reference synthesis product with quartz powder. A high amount of 


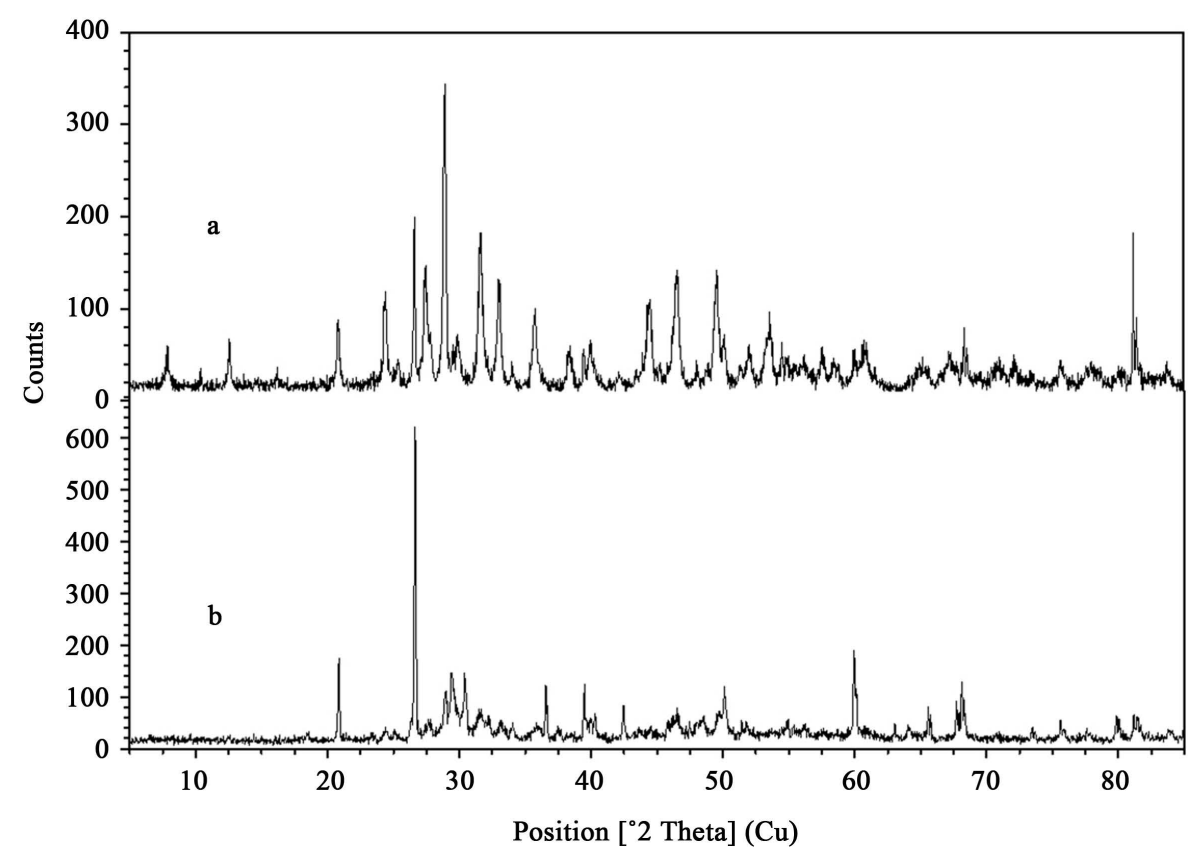

Figure 1. XRD analysis of the synthesis products without additives: (a) Powder sample; (b) Pellet sample.

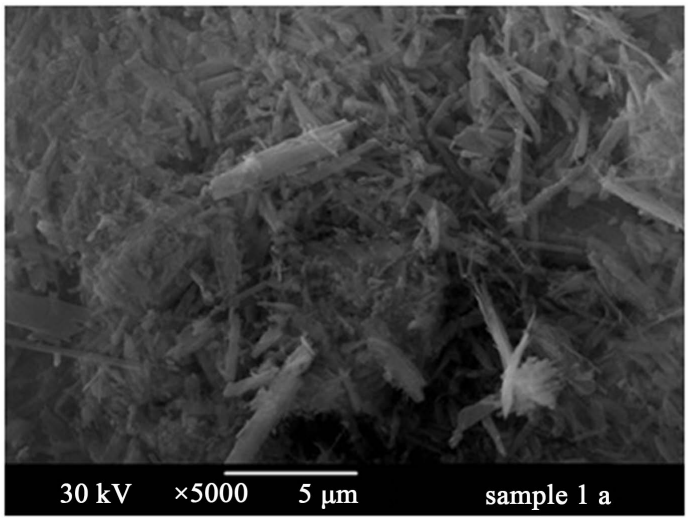

Figure 2. SEM image of the product of the reference synthesis (powder).

Table 2. Quantitative phase analysis of the products of reference synthesis (powder).

\begin{tabular}{cccc}
\hline Phase & Composition $^{*}$ & Amount (M.-\%) & Amount (without quartz) (M.-\%) \\
\hline Xonotlite & $\mathrm{C}_{6} \mathrm{~S}_{6} \mathrm{H}$ & 80.57 & 83.27 \\
11 Å Tobermorite & $\mathrm{C}_{5} \mathrm{~S}_{6} \mathrm{H}_{5}$ & 16.19 & 16.73 \\
Quartz & $\mathrm{SiO}_{2}$ & 3.24 & - \\
\hline
\end{tabular}

${ }^{*} \mathrm{CSH}$ acc. [20].

needle-like CSH-phases of 2 - $5 \mu \mathrm{m}$ length can be seen partly embedded in quartz powder. The EDX analysis of the surface of a needle is given in Figure 3. A C/S of 0.92 can be estimated from the data.

The results of SEM investigation of the reference products from synthesis with the pellet are summarized in Figures 4-6. Already the overview image (Figure 4) shows a high amount of CSH-phases with needle-like morphology. Higher magnification of Figure 5 reveals a more or less connected network of the crystals. Highest 


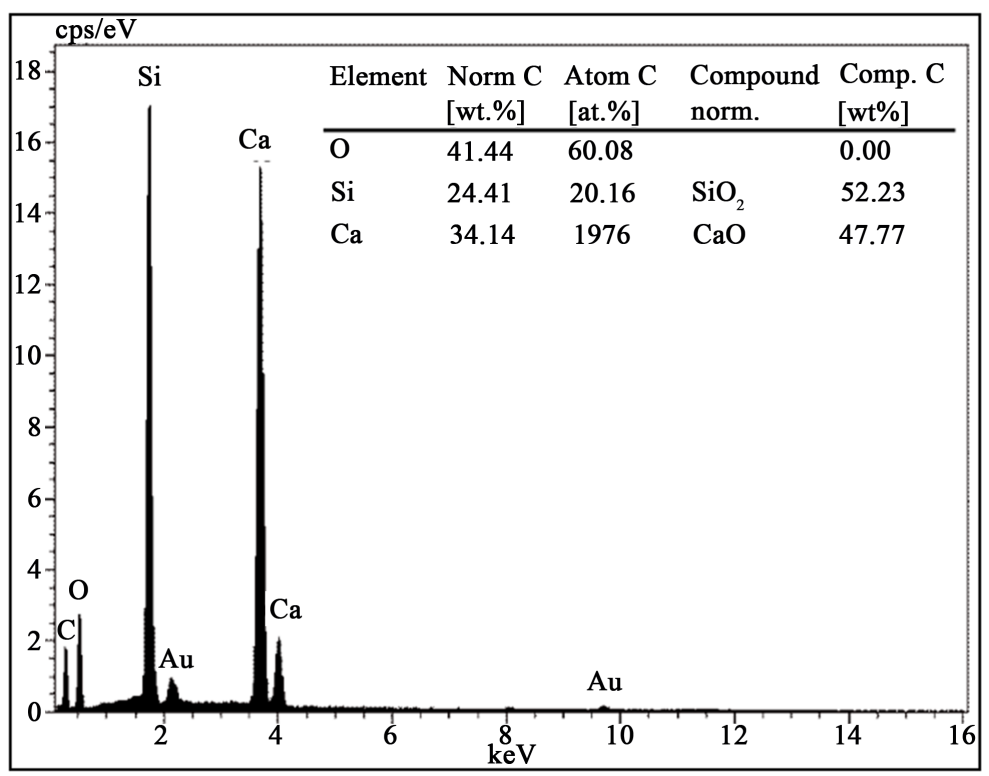

Figure 3. EDX analysis of the product of the reference synthesis (powder).

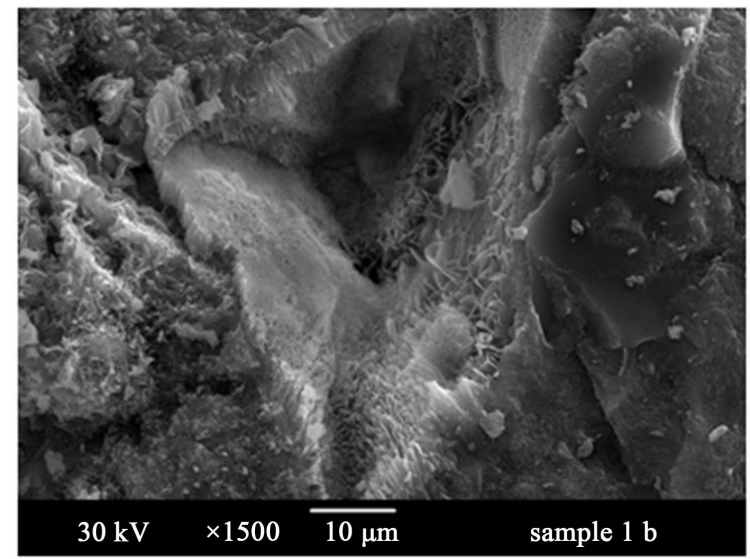

Figure 4. SEM image of the product of reference synthesis (pellet), low magnification for overview.

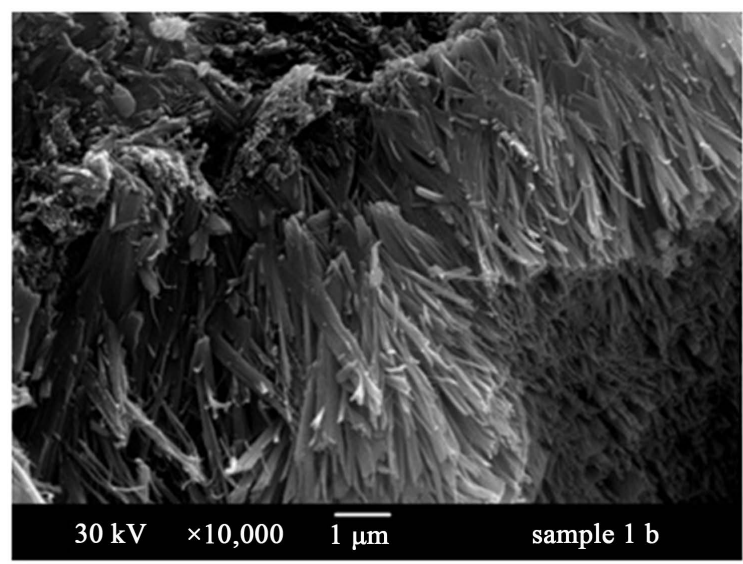

Figure 5. SEM image of the product of reference synthesis (pellet), crystal network at higher magnification. 


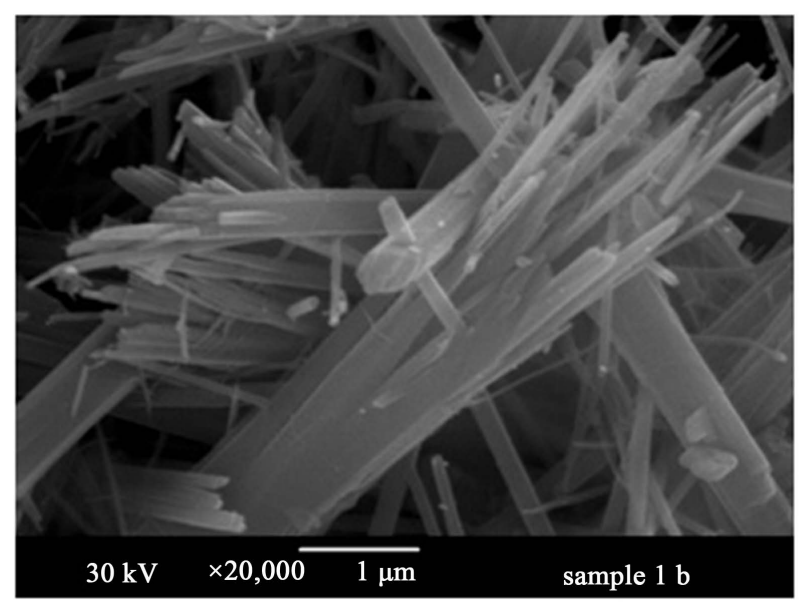

Figure 6. SEM image of the product of reference synthesis (pellet), fragmented crystals at highest magnification.

magnification (Figure 6) indicates a fragmented structure of the crystals and crystal sizes around 2 - $3 \mu \mathrm{m}$ and higher. The EDX analysis (see Figure 7) gives a C/S value of 0.75.

\subsubsection{The Products of Synthesis with Addition of Sucrose}

The X-ray powder patterns of syntheses products obtained under addition of sucrose are summarized in Figure 8. A high amount of quartz can be seen in both patterns (synthesis with powder: a; synthesis with pellet: b). Lines of calcite (PDF 10 - 400) and scawtite $\mathrm{Ca}_{7}\left(\mathrm{Si}_{6} \mathrm{O}_{18}\right)\left(\mathrm{CO}_{3}\right) \cdot 2 \mathrm{H}_{2} \mathrm{O}\left(\mathrm{C}_{7} \mathrm{~S}_{6} \mathrm{H}_{3} \mathrm{C}\right.$; PDF 31-261) were further analysed (see main reflections between $29.5^{\circ}(2 \theta)$ and $30.5^{\circ}(2 \theta)$ ) but with higher intensities for the synthesis product from powder. Results from quantitative Rietveld refinement of the product from powder are summarized in Table 3, which also includes the amounts of scawtite and calcite after subtraction of the strong quartz fraction.

The results of the SEM investigation of the synthesis products with addition of sucrose show fine grained $\mathrm{CSH}$-phases on very low scale (Figure 9). EDX analysis of the small CSH particles beside quartz gives a C/S value of 1.06 (Figure 10).

The synthesis with the pellet under addition of sucrose shows very few but somewhat bigger CSH-crystals with needle-like morphology (Figure 11), grown in the pore space between quartz particles. The EDX analysis of Figure 12 reveals a C/S ratio of 0.8 . As tobermorite could not detected by XRD the crystals are maybe tobermorite in a low amount under the XRD detection limit or CSH scawtite closely connected with quartz.

Also big rhombohedral crystals of calcite were observed within the product (Figure 13). EDX analysis discloses a high amount of calcium (Figure 14).

\subsubsection{The Products of Synthesis with Addition of Calcium Formate}

The X-ray powder pattern of the product from powder under addition of calcium formate (Figure 15(a)) shows quartz and xonotlite as the main phases. Some weak signals of calcite were also detected. Quantitative results according to Rietveld refinement of the pattern of this product from powder are summarized in Table 4, which also includes the amounts of xonotlite and calcite after subtraction of the quartz fraction.

In the XRD pattern of the product from the pellet (Figure 15(b)) mainly quartz beside lower amounts of xonotlite and somewhat more calcite were detected.

SEM investigation of the synthesis product with powder and addition of calcium formate shows crystallisation of CSH-phases with needle-like morphology (Figure 16). The crystals have a size of $20 \mu \mathrm{m}$ up to $50 \mu \mathrm{m}$. XRD results and also the morphology exhibits the formation of xonotlite. Beside separated xonotlite crystals also smaller more net-like CSH-phases were observed. If these phases are former tobermorites under advanced degradation or pre-stage xonotlites is unclear up to now. The low C/S ratio of 0.56 , obtained from the EDX analysis of a needle-like crystal, given in Figure 17, clearly indicate a covering of the crystal surface with silicate.

SEM analysis of the synthesis product with the pellet and addition of calcium formate shows xonotlite beside 


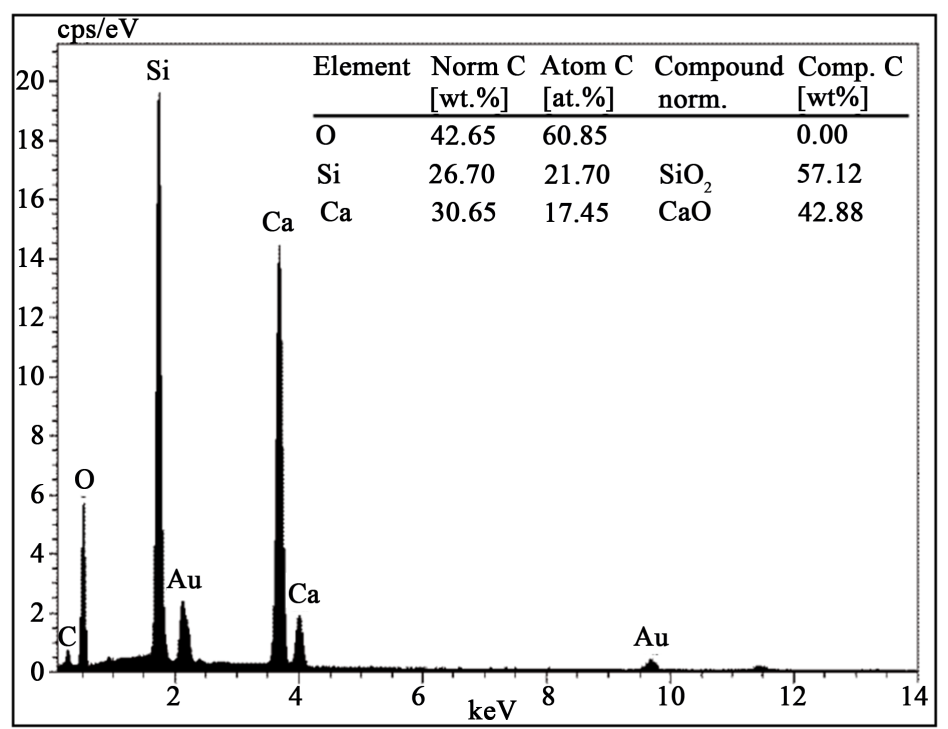

Figure 7. EDX analysis of the products of the reference synthesis (pellet).

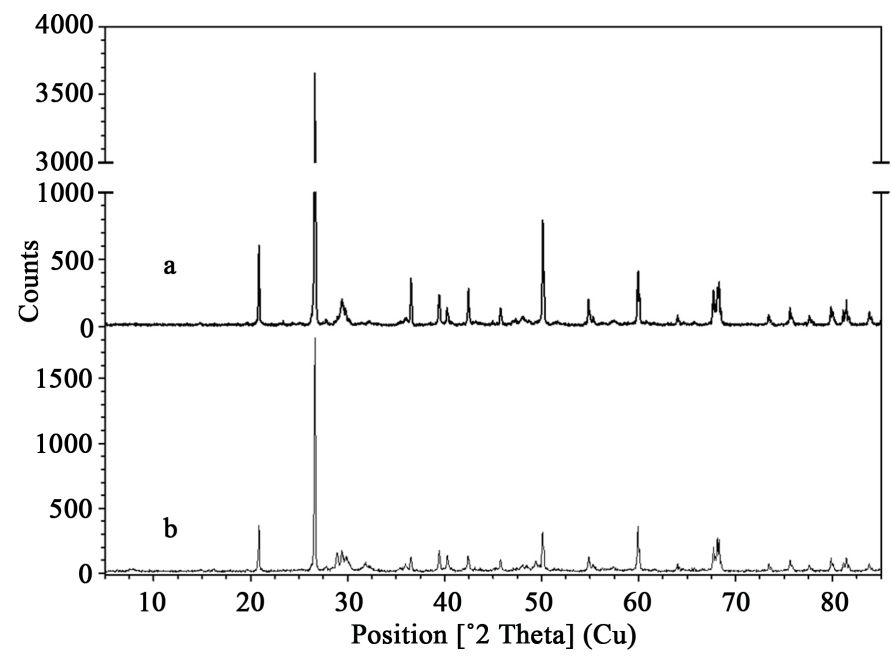

Figure 8. XRD analysis of the synthesis products with addition of sucrose: (a) Powder sample; (b) Pellet sample.

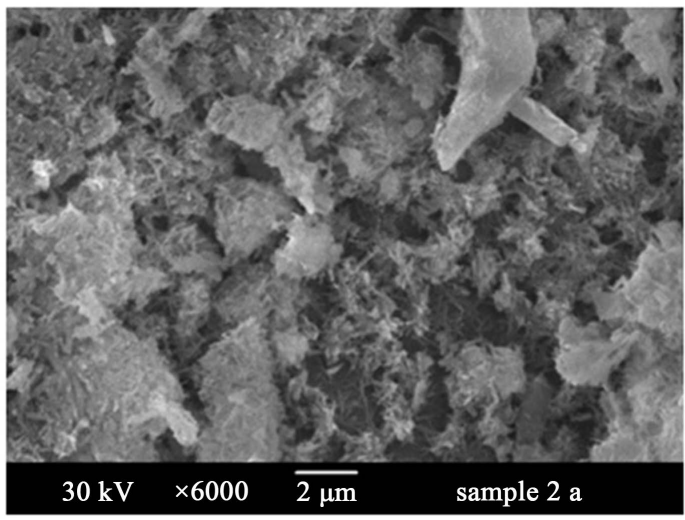

Figure 9. SEM image of the product of synthesis with addition of sucrose (powder). 


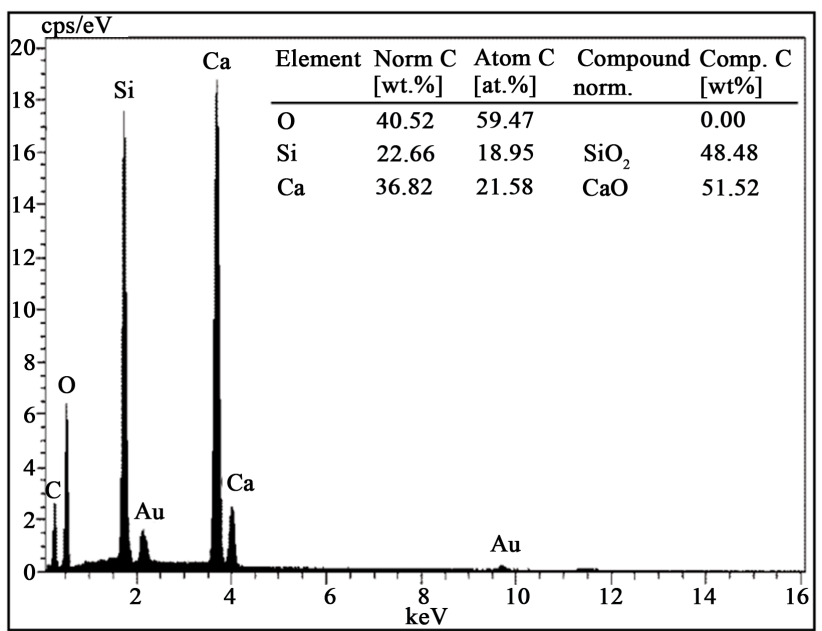

Figure 10. EDX analysis of the fine grained CSH particles between quartz in the product of synthesis with addition of sucrose.

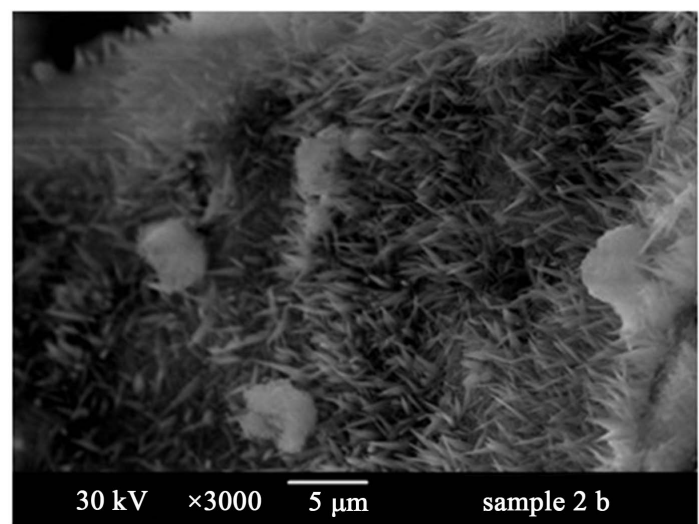

Figure 11. SEM image of the products of synthesis with addition of sucrose (pellet).

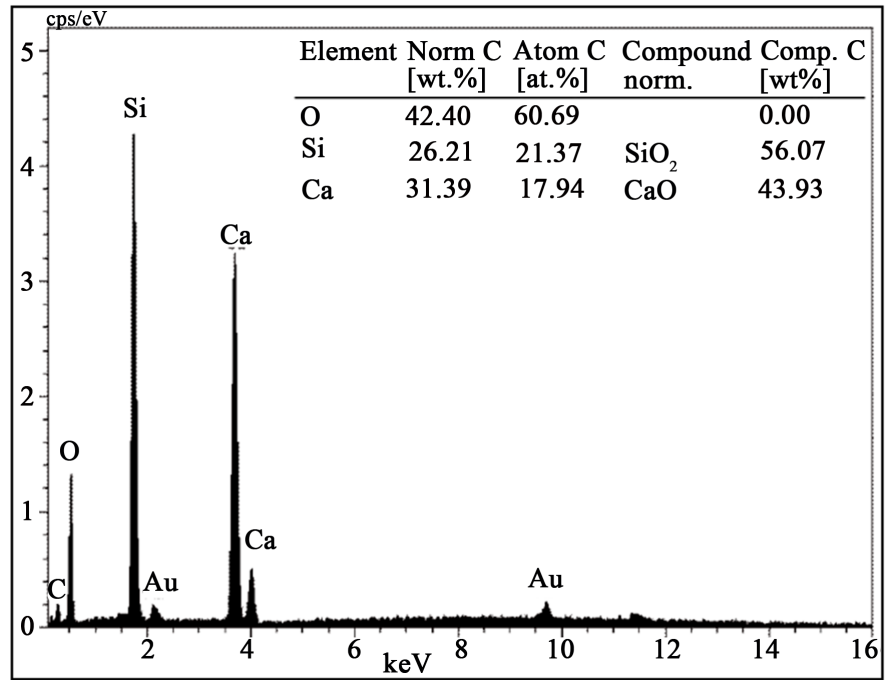

Figure 12. EDX analysis of the products of synthesis with addition of sucrose (pellet). 


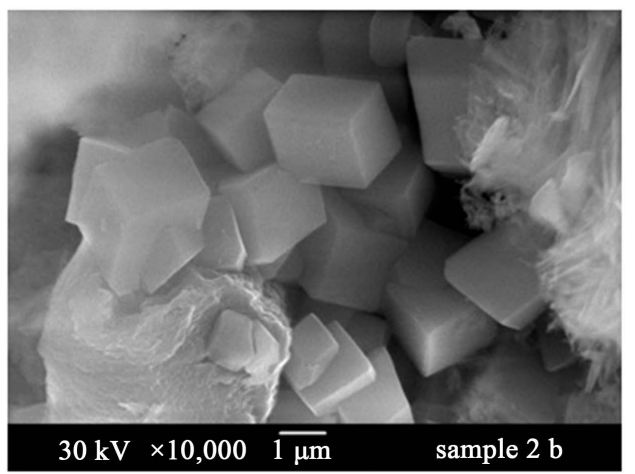

Figure 13. SEM image of the product of synthesis with addition of sucrose (pellet).

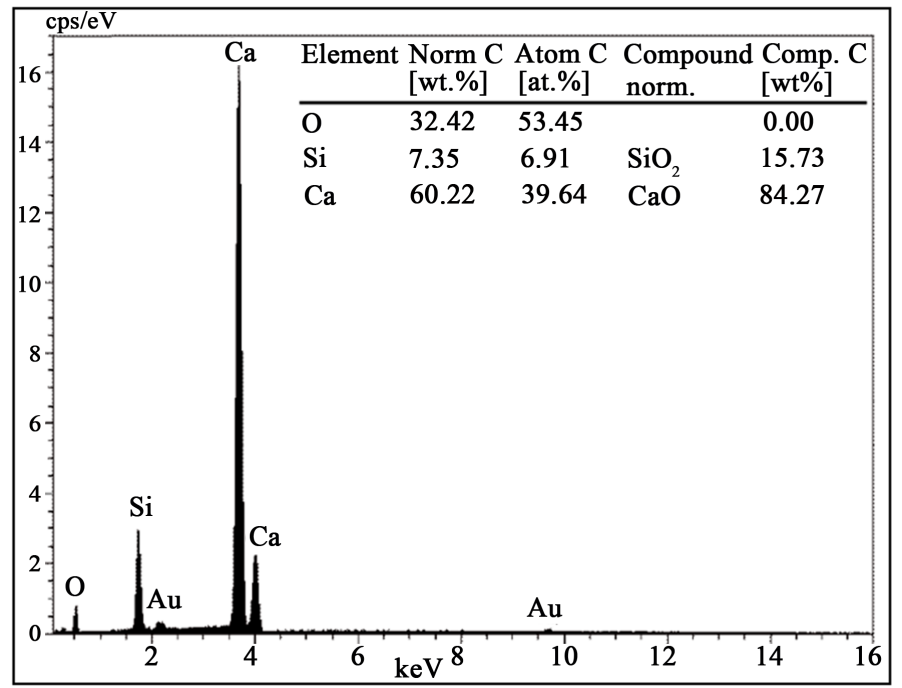

Figure 14. EDX analysis of the product of synthesis with addition of sucrose (pellet).

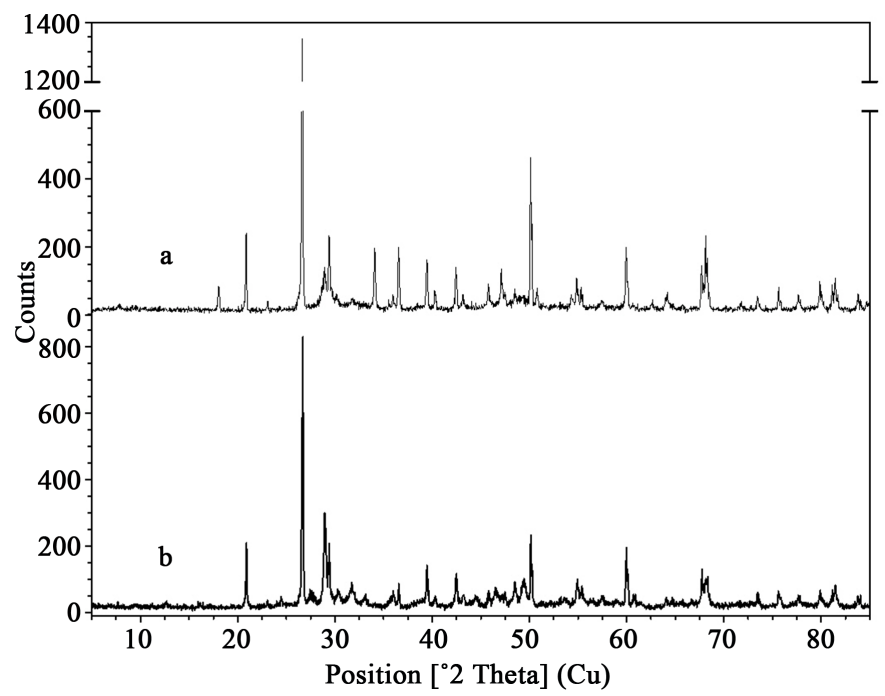

Figure 15. XRD analysis of the synthesis products with addition of calcium formate: (a) Powder sample; (b) Pellet sample. 


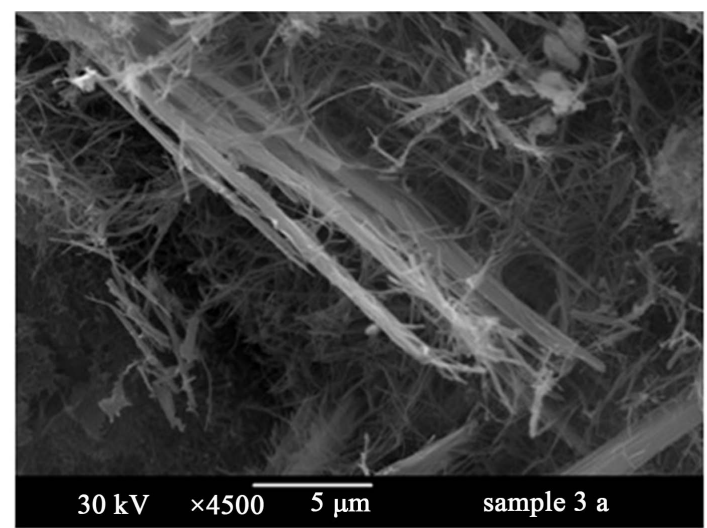

Figure 16. SEM image of the product of synthesis with addition of calcium formate (powder).

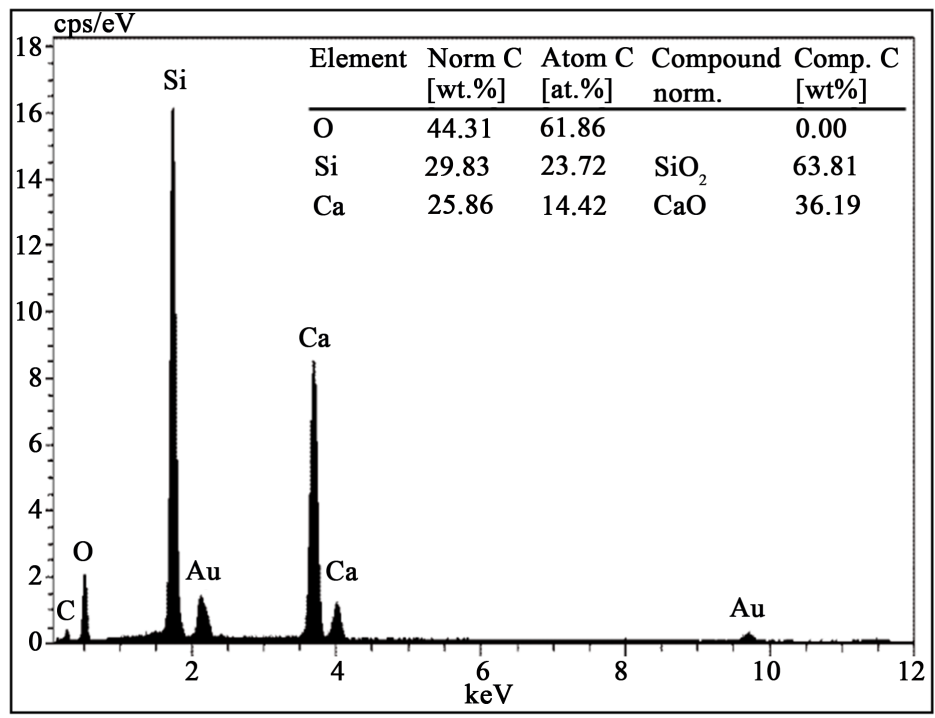

Figure 17. EDX analysis of the product (CSH needle) of synthesis with addition of calcium formate (powder).

Table 3. Quantitative phase analysis of the products from synthesis with sucrose (powder).

\begin{tabular}{cccc}
\hline Phase & Formula $^{*}$ & Amount (M.-\%) & Amount, without quartz (M.-\%) \\
\hline Quartz & $\mathrm{SiO}_{2}$ & 50.35 & - \\
Scawtite & $\mathrm{C}_{7} \mathrm{~S}_{6} \mathrm{H}_{3} \mathrm{C}$ & 25.20 & 50.76 \\
Calcite & $\mathrm{CaCO}_{3}$ & 24.45 & 49.24 \\
\hline
\end{tabular}

${ }^{*}$ CSH acc. [20].

Table 4. Quantitative phase analysis of the products from synthesis with calcium formate (powder).

\begin{tabular}{cccc}
\hline Phase & Formula & Amount (M.-\%) & Amount, without quartz (M.-\%) \\
\hline Xonotlite & $\mathrm{C}_{6} \mathrm{~S}_{6} \mathrm{H}_{2}$ & 51.26 & 71.11 \\
Quartz & $\mathrm{SiO}_{2}$ & 27.92 & - \\
Calcite & $\mathrm{CaCO}_{3}$ & 20.83 & 28.89 \\
\hline
\end{tabular}

${ }^{*} \mathrm{CSH}$ acc. [20]. 
small amounts of to bermorite in band-shaped crystals up to $5 \mu \mathrm{m}$, which grow into the pore space (see Figure 18). The EDX measurement given in Figure 19, exhibits a C/S ratio of 1.36 according to intergrowths with calcite in agreement with XRD analysis.

\subsubsection{The Products of Synthesis with Addition of Calcium Chloride Dihydrate}

Formation of mainly xonotlite beside somewhat fewer amount of tobermorite and quartz can be derived from the XRD results of the synthesis with powder, given in Figure 20(a). Quantitative results according to Rietveld refinement of the pattern of this product from powder are summarized in Table 5, which also includes the amounts of xonotlite and tobermorite after subtraction of the quartz fraction.

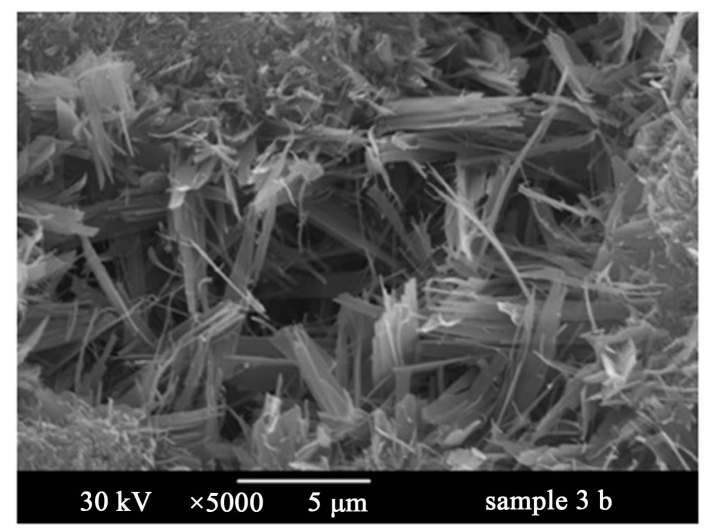

Figure 18. SEM image of the product of synthesis with addition of calcium formate (pellet).

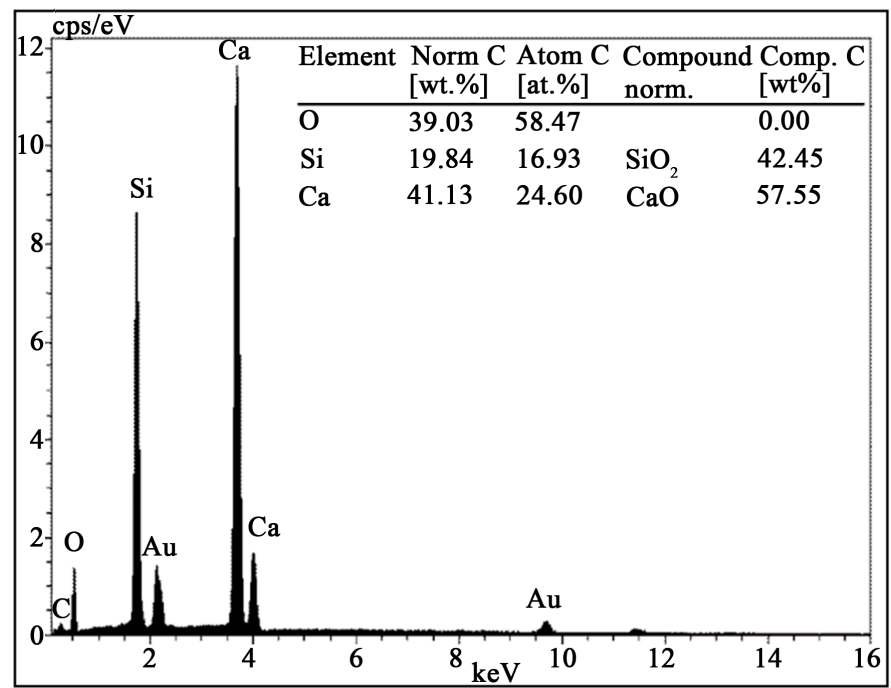

Figure 19. EDX analysis of CSH needles of synthesis with addition of calcium formate (pellet).

Table 5. Quantitative phase analysis of the products from synthesis with calcium chloride dihydrate (powder).

\begin{tabular}{cccc}
\hline Phase & Formula & Amount (M.-\%) & Amount, without quartz (M.-\%) \\
\hline Xonotlite & $\mathrm{C}_{6} \mathrm{~S}_{6} \mathrm{H}_{2}$ & 56.58 & 65.57 \\
$11 \AA$ Tobermorite & $\mathrm{C}_{5} \mathrm{Si}_{6} \mathrm{H}_{5}$ & 29.71 & 34.43 \\
Quartz & $\mathrm{SiO}_{2}$ & 13.70 & - \\
\hline
\end{tabular}

${ }^{*}$ CSH acc. [20]. 


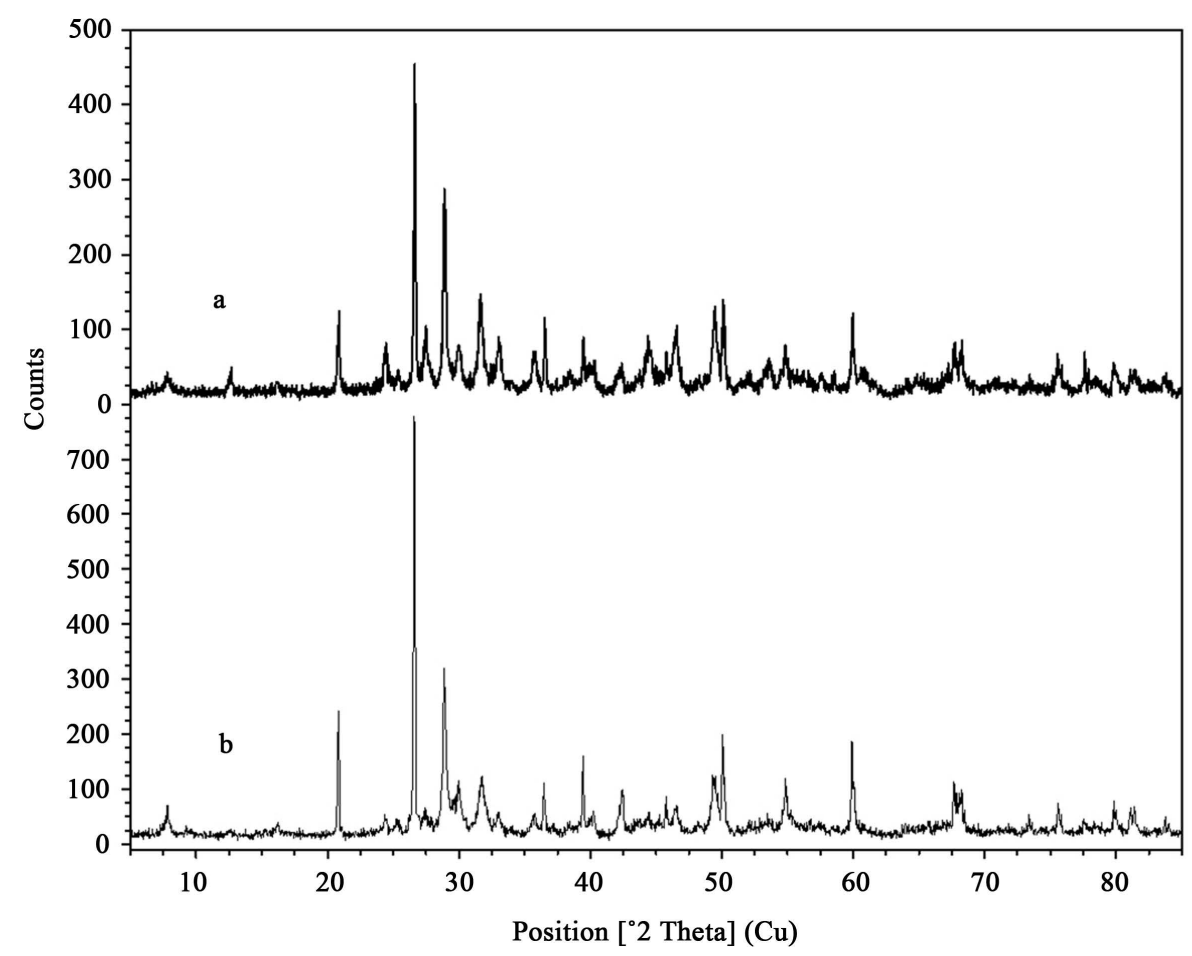

Figure 20. XRD analysis of the synthesis products with addition of calcium chloride dehydrate: (a) Powder sample; (b) Pellet sample.

In contrast qualitative estimation of the XRD pattern of the product from pellet synthesis crystallization of somewhat more tobermorite can be found compared with xonotlite, beside the usual parts of quartz.

Figure 21 shows a typical SEM image of the synthesis product, obtained from powder under addition of calcium chloride dihydrate. In accordance with XRD, high amounts of CSH-phases were observed. The CSH crystals show a needle-like morphology of 3 - $4 \mu \mathrm{m}$ in size.

The EDX analysis, given in Figure 22 indicates a C/S ratio of 1.0, as to be expected for xonotlite. Also an amount of $2.55 \mathrm{M}$. \% chlorine was detected, resulting from the additive calcium chloride dihydrate.

SEM investigation of the product of synthesis with the pellet under addition of calcium chloride dihydrate, shown in Figure 23, reveals CSH-phases similar to the synthesis with powder. The crystals have a needle-like morphology with a size of about $10 \mu \mathrm{m}$ (Figure 23). EDX analysis, given in Figure 24, indicates a C/S ratio of 0.91 for this material.

A further SEM image at somewhat higher magnification is shown in Figure 25. Large crystals, which mainly grew inside the pore space with a card-shaped morphology can be seen. The EDX analysis of these crystals reveals a $\mathrm{C} / \mathrm{S}$ ratio of 0.83 characteristic for tobermorite (see Figure 26).

\subsection{FTIR Spectroscopy}

Figure 27 summarizes the FTIR-spectra of the products of all experiments. The spectra of the syntheses with powder (a) always exhibited a higher degree of absorption as well as more distinct signals compared to the spectra of the products synthesized with pellets (b). The spectrum of synthesis with powder and without additives (Figure 27, sample 1a) reveals two strong absorption bands in the range of the deformation vibrations of $\mathrm{SiO}_{4}$-tetrahedra $\left(400-540 \mathrm{~cm}^{-1}\right)$ and three signals with shoulders due to Si-O stretching vibrations $(900-1200$ $\mathrm{cm}^{-1}$ ) [30]. Also Si-O-Si bending vibrations induce a signal at $671 \mathrm{~cm}^{-1}$.

Those absorption bands occur quite similar in all the spectra of this study and indicate silicate chain structures [30]. All samples show $\mathrm{CO}_{3}^{2-}$ vibrations of carbonate in the range of $1400-1500 \mathrm{~cm}^{-1}$ and at $876 \mathrm{~cm}^{-1}$ as a shoulder [31]. For the pellets of the reference (1b) and the products of the syntheses with addition of calcium formate (3b) the signals of carbonates have a higher intensity compared to the powder samples (1a and 3a). The 


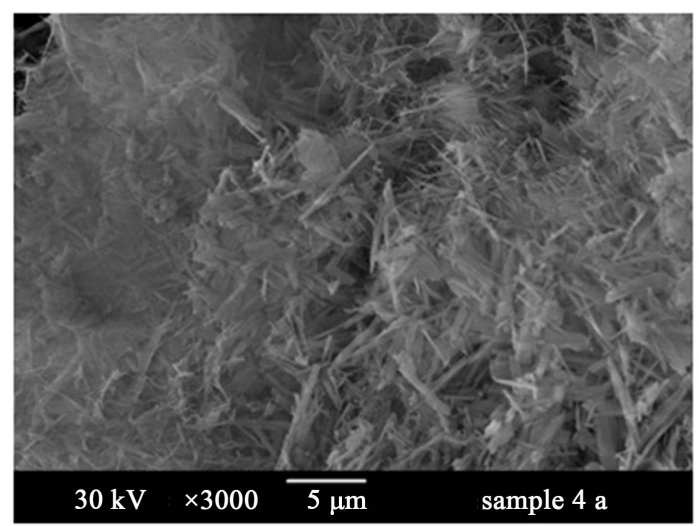

Figure 21. SEM image of the product of synthesis with addition of calcium chloride dihydrate (powder).

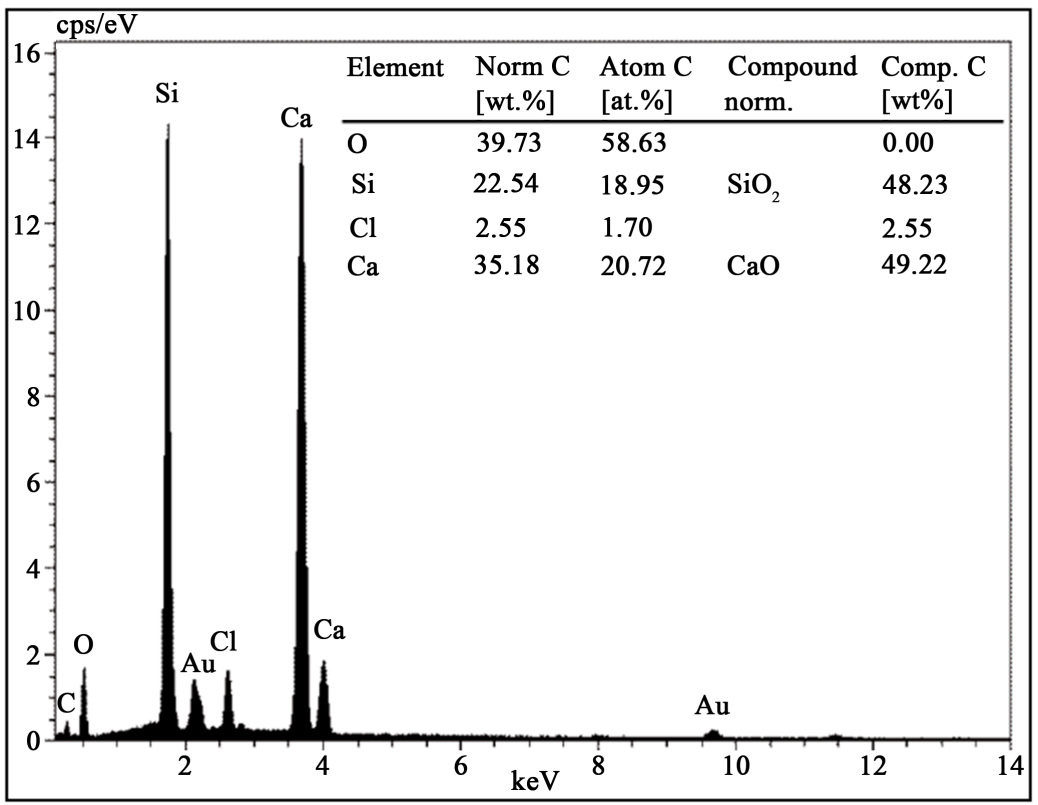

Figure 22. EDX Analysis of the product of synthesis with addition of calcium chloride dihydrate (powder).

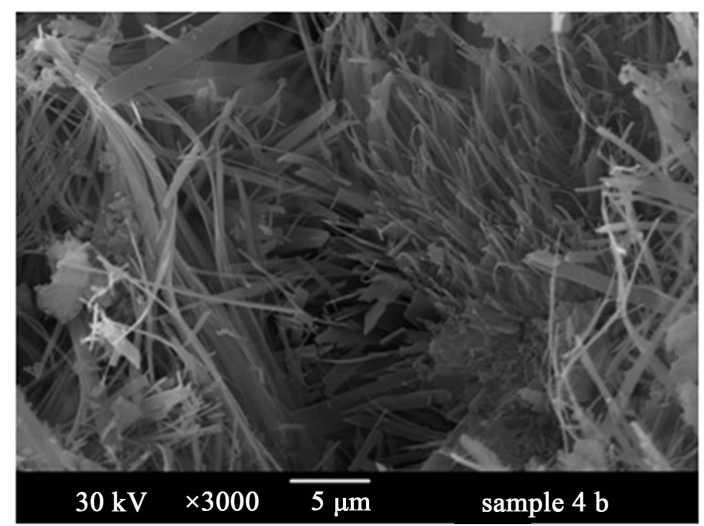

Figure 23. SEM image of the product of synthesis with addition of calcium chloride dihydrate (pellet). 


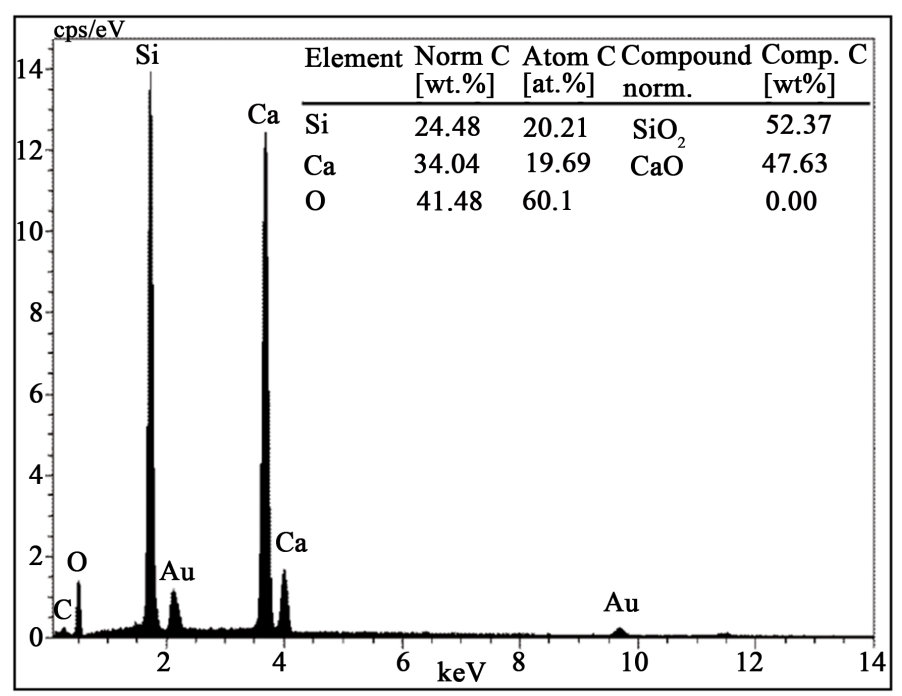

Figure 24. EDX analysis of the crystals according to Figure 23 of synthesis with addition of calcium chloride dihydrate (pellet).

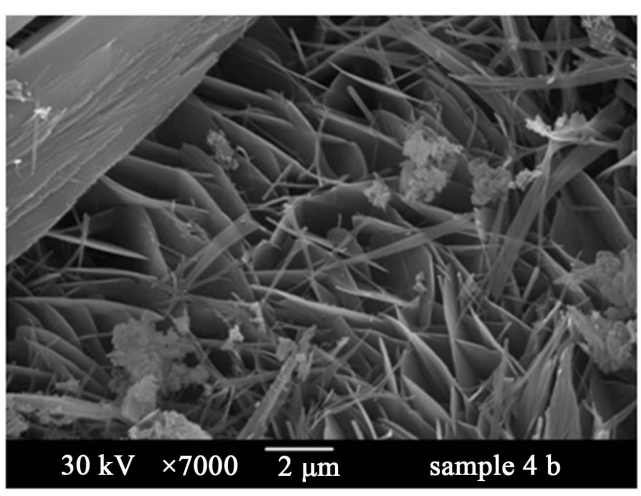

Figure 25. SEM image of the product of synthesis with addition of calcium chloride dihydrate (pellet). Crystals within the pore.

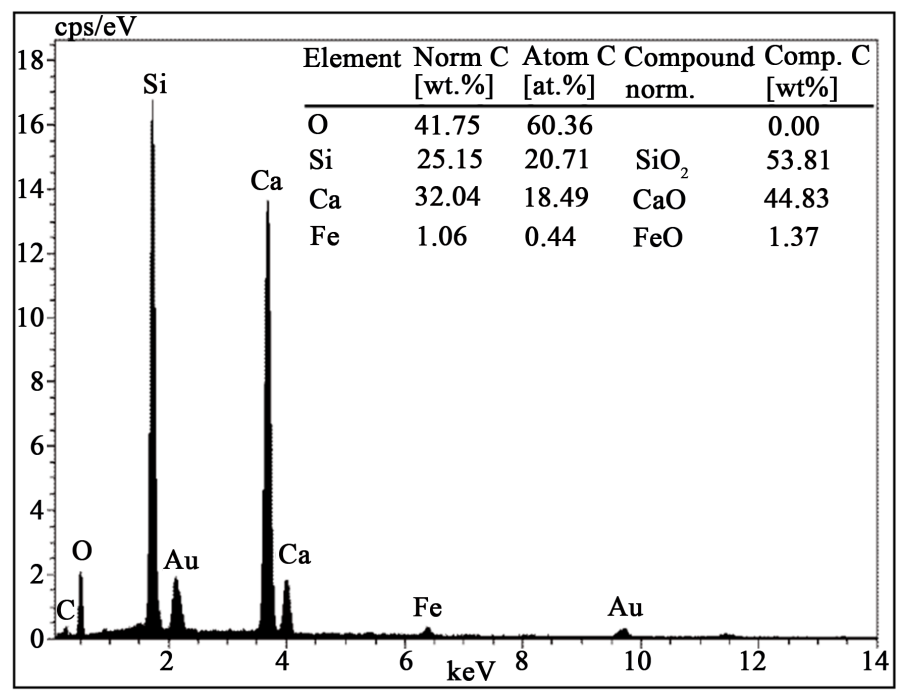

Figure 26. EDX analysis of the crystals according to Figure 25 of product of synthesis with addition of calcium chloride dihydrate (pellet). 


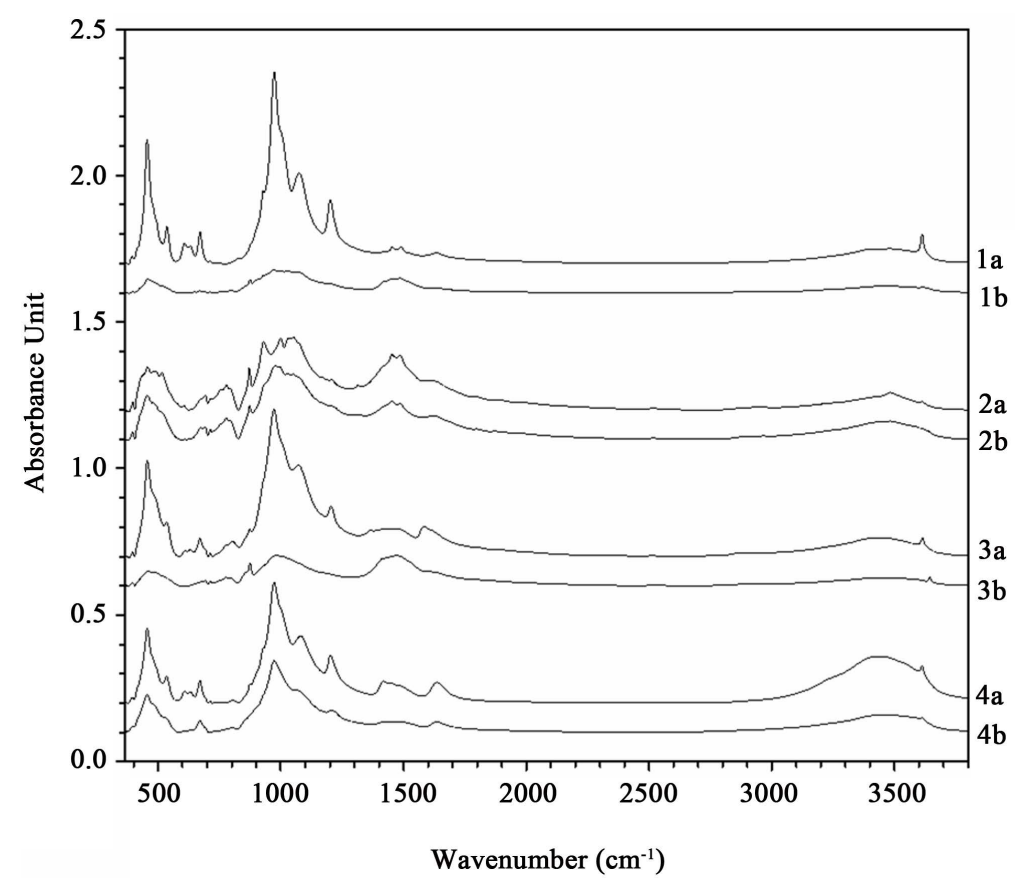

Figure 27. FTIR-spectra of the products of synthesis with powder (a) and pellet (b) and without additives (1), with addition of sucrose (2), calcium formate (3) and calcium chloride dihydrate (4).

absorption bands of water occur at about $1634 \mathrm{~cm}^{-1}$ and between $2800-3700 \mathrm{~cm}^{-1}$ [31]. They are present in all the spectra but the spectrum of the products of synthesis with addition of calcium chloride dihydrate (4a) has a much higher intensity. Signals around $3600 \mathrm{~cm}^{-1}$ are due to vibrations of hydroxyl groups [31]. Possible types of vibrations are $\mathrm{Si}-\mathrm{OH}, \mathrm{Ca}-\mathrm{OH}$ and $\mathrm{OH}^{-}$[31]. The $\mathrm{OH}$-absorption band in the spectra of sample 1a, 3a, 3b and 4a is distinct and has a high intensity. The spectra of the syntheses with sucrose do not show $\mathrm{OH}$-vibrations. Also the $\mathrm{Si}-\mathrm{O}$ stretching and the $\mathrm{SiO}_{4}$ bending vibrations of the spectra $2 \mathrm{a}$ and $2 \mathrm{~b}$ indicate broad, overlapping signals in contrast to distinct absorption bands of the other samples. The spectra of the products of syntheses with addition of calcium formate ( $3 a$ and $3 b$ ) and calcium chloride dihydrate (4a and $4 b$ ) have a strong correlation to the spectra of the reference ( $1 \mathrm{a}$ and $1 \mathrm{~b})$. But the absorption bands of the reference are more distinctive and have a higher intensity.

\section{Discussion and Conclusion}

For the general evaluation of the influence of the different additives studied in the present work, the qualitative estimation of phase formation for all experiments is summarized in Table 6. From this overview, based on XRD, it can be derived, that the insertions of additives have a remarkable effect on the progress of CSH-phase formation during the hydrothermal process.

The following aspects have to be discussed for a comparative characterization individual behavior of an additive on the reaction process:

(i) the degree of conversion during the whole reaction;

(ii) the overall amounts of CSH phase formation, independent of an individual phase;

(iii) the ratio of xonotlite/other CSH (tobermorite, scawtite); and last not least

(iv) the crystal quality according to morphology and size of the crystals.

The amount of remaining quartz after each reaction is representative for the degree of conversion (i). The quantitative values from Rietveld refinements for products under use of powdery educts show the following ranking order (starting with the best result):

reference $\rightarrow$ calcium chloride dehydrate $\rightarrow$ calcium formate $\rightarrow$ succrose

The same ranking can be estimated qualitatively from XRD (Table 6) for synthesis with pellets. 
Table 6. Results of the X-ray diffraction.

\begin{tabular}{|c|c|c|c|c|c|c|c|c|}
\hline Additive & * & $(\mathbf{C}+\mathbf{A}) / \mathrm{S}$ & $\mathrm{A} / \mathrm{C}$ & Tob & Xo & Sc & $\mathbf{Q z}$ & Cal \\
\hline \multirow[b]{2}{*}{ Reference } & $1 \mathrm{a}$ & 0.83 & - & $\circ$ & $\bullet$ & & $(\cdot)$ & \\
\hline & $1 b$ & 0.83 & - & 0 & $\circ$ & & $\bullet$ & \\
\hline \multirow{2}{*}{ Sucrose } & $2 \mathrm{a}$ & 0.54 & 0.24 & & & $\circ$ & $\bullet$ & $\circ$ \\
\hline & $2 b$ & 0.54 & 0.24 & $\circ$ & $\circ$ & $\circ$ & $\bullet$ & \\
\hline \multirow{2}{*}{ Calcium formate } & 3a & 0.80 & 0.49 & & $\bullet$ & & $\circ$ & $\circ$ \\
\hline & $3 b$ & 0.80 & 0.49 & & $\circ$ & & $\bullet$ & $\circ$ \\
\hline \multirow{2}{*}{$\begin{array}{l}\text { Calcium chloride } \\
\text { dihydrate }\end{array}$} & $4 a$ & 0.80 & 0.49 & $\circ$ & $\bullet$ & & $(\cdot)$ & \\
\hline & $4 \mathrm{~b}$ & 0.80 & 0.49 & 0 & $\circ$ & & $\bullet$ & \\
\hline
\end{tabular}

${ }^{*} \mathrm{a}=$ powdered, $\mathrm{b}=$ pressed educts; $\bullet=$ high, $\mathrm{o}=$ low amount $(\cdot)$ very low amount, Tob $=11-\AA$ tobermorite, Xo $=$ xonotlite, Sc $=$ scawtite, Qz $=$ quartz, Cal = calcite.

Again an equal sequence is found for the overall amounts of CSH phase formation, independent of an individual phase (ii) and for the ratio of xonotlite: tobermorite or scawtite (iii), again for synthesis with powder as well as with pellet.

It has to be mentioned here, that the comparison of reactions with powders or pellets shows general lower reaction rates for pellets and hence more quartz and fewer CSH within these products. Here the reduced reaction space compared with crystallization within the liquid phase under use of powders and $20 \mathrm{ml}$ water is responsible for the lower conversion into CSH-phases. However, a reduced reaction area introduces a formation of CSH in card-shaped structure resulting in a high stability of the building material, like, e.g. limesand stone [20].

According to (iv) the ranking is somewhat deviating. As the morphology is relative similar as both synthesis products from powders with calcium chloride dehydrate and calcium formate appear as needles, the crystal size differs. Were needles of $5-10 \mu \mathrm{m}$ in size were found for powder syntheses with formate, much longer ones (10$20 \mu \mathrm{m}$ ) were observed with calcium chloride dehydrate. Using pellets again more band or card shaped crystals of uniform size between 5 - $10 \mu$ m occurred.

In contrast syntheses with sucrose yield to the $\mathrm{CSH}$-phase scawtite $\mathrm{C}_{7} \mathrm{~S}_{6} \mathrm{H}_{3} \mathrm{C}$ instead of tobermorite and xonotlite. From the literature it is known that at low temperatures sucrose and calcium ions form a Ca-saccharate complex, whereby further reactions with $\mathrm{SiO}_{2}$ and $\mathrm{H}_{2} \mathrm{O}$ to $\mathrm{CSH}$-phases could be prevented [32]. At higher temperatures $\left(160^{\circ} \mathrm{C}-180^{\circ} \mathrm{C}\right)$ sucrose dissociates. The solubility of quartz depends on alkaline conditions, ruled by the availability of $\mathrm{Ca}(\mathrm{OH})_{2}$. Therefore at the beginning of the reaction calcium is consumed by sucrose and the solubility of quartz is lower and a less amount of $\mathrm{SiO}_{2}$ is available for the formation of CSH-phases. At elevated temperatures dissolution products of the Ca-saccharate complex like calcium ions and carbonate groups seem to favour the formation of scawtite.

The results with calcium formate are surprising. Former experiments on tobermorite synthesis at $200^{\circ} \mathrm{C}$ already showed the retarding effect of this additive on the formation of $\mathrm{C}_{5} \mathrm{~S}_{6} \mathrm{H}_{5}$ [26]. The results of the present study of synthesis at $220^{\circ} \mathrm{C}$ confirm this observation for tobermorite but show in contrast a surprisingly high amount of xonotlite and calcite. Remaining parts of portlandite and quartz, as during $200^{\circ} \mathrm{C}$ syntheses in [26], were not found in the present study. Future experiments must clarify the role of higher temperature and the question if the formation of xonotlite is more insensitive against the Ca-formate effect.

From all three additives calcium chloride dihydrate yield to highest amounts of CSH in close resemblance to the results of the reference syntheses but with higher portions of tobermorite than xonotlite. Further experiments must clarify if this behavior is ruled by $\mathrm{pH}$-value [14]-[16] hand in hand with the ionic potential of the additional $\mathrm{Ca}$ and $\mathrm{Cl}$ ions in the reaction system [10]-[12].

\section{References}

[1] Taylor, H.F.W. (1990) Cement Chemistry. Academic Press, London.

[2] Dodson, V. (1990) Concrete Admixtures. Van Nostrand Reinhold, New York. http://dx.doi.org/10.1007/978-1-4757-4843-7 
[3] Rixom, R. and Mailgavanam, N. (1999) Chemical Admixtures for Concrete. Spon Press, Taylor and Francis, Oxford, New York. http://dx.doi.org/10.4324/9780203017241

[4] Hermann, K. (1995) Chemikalien, die auf Beton wirken. Cement Bulletin, 63, 3.

[5] Ludwig, U. (1983) Über die Wirkung von Verzögerern auf das Erstarren der Zemente. Beton-Information, $23,31$.

[6] Thomas, N.L. and Birchall, J.D. (1983) The Retarding Action of Sugars on Cement Hydration. Cement and Concrete Research, 13, 830-842. http://dx.doi.org/10.1016/0008-8846(83)90084-4

[7] Thomas, N.L. and Birchall, J.D. (1984) A Reply to a Discussion by S Chatterji of "The Retarding Action of Sugars on Cement Hydration” by N L Thomas and J D Birchall. Cement and Concrete Research, 14, 761-762. http://dx.doi.org/10.1016/0008-8846(84)90042-5

[8] Birchall, J.D. and Thomas, N.L. (1984) The Mechanism of Retardation of Setting of OPC by Sugars. Br. Ceram. Proc., 35, 305-315.

[9] Ludwig, U. and Urrutia, C. (1989) Zum Mechanismus der Wirkung von Saccharose auf das Erstarren und Erhärten von Zementen. Zement-Kalk-Gips, 42, 431-436.

[10] Kantro, D.L. (1975) Tricalcium Silicate Hydration in the Presence of Various Salts. Journal of Testing and Evaluation, 3, 312. http://dx.doi.org/10.1520/JTE10661J

[11] Kondo, R., Daimon, M., Sakai, E. and Ushiyama, H. (1977) Influence of Inorganic Salts on the Hydration of Tricalcium Silicate. Journal of Applied Chemistry and Biotechnology, 27, 191-197. http://dx.doi.org/10.1002/jctb.5020270128

[12] Wilding, C.R., Walter, A. and Double, D.D. (1984) A Classification of Inorganic and Organic Admixtures by Conduction Calorimetry. Cement and Concrete Research, 14, 185-194. http://dx.doi.org/10.1016/0008-8846(84)90103-0

[13] Singh, N.B. and Abha, K. (1983) Effect of Calcium Formate on the Hydration of Tricalcium Silicate. Cement and Concrete Research, 13, 619-625. http://dx.doi.org/10.1016/0008-8846(83)90050-9

[14] Brown, B.W., Harner, C.L. and Prosen, E.J. (1986) The Effect of Inorganic Salts on Tricalcium Silicate Hydration. Cement and Concrete Research, 16, 17-22. http://dx.doi.org/10.1016/0008-8846(86)90063-3

[15] Massazza, F. and Gilioli, C. (1983) Contribution to the Alinite Knowledge II. Cemento, 2, 101-106.

[16] Cheeseman, C.R. and Asavapisit, S. (1999) Effect of Calcium Chloride on the Hydration and Leaching of Lead-Retarded Cement. Cement and Concrete Research, 29, 885-892. http://dx.doi.org/10.1016/S0008-8846(99)00053-8

[17] Gartner, E.M. and Gaidis, J.M. (1989) Hydration Mechanisms, I. In: Skalny, J.P., Ed., Materials Science of Concrete, The American Ceramic Society, Westerville, 95-125.

[18] Gundlach, H. (1969) Dampfgehärtete Baustoffe. Bauverlag GmbH, Wiesbaden.

[19] Mörtel, H. (1978) Die Gefügeentwicklung der CSH-Phasen in Kalksandstein im Temperaturbereich von $120-250^{\circ} \mathrm{C}$ bei Haltezeiten von 1/2 Stunden-2 Wochen. Folgerungen für die Eigenschaften von Kalksilikatprodukten. Internationales Symposium über die Beziehungen zwischen den Eigenschaften von KS-Produkten und den Bindemittelaufbau, Karlsruhe 1978, Session I, Vortrag 4, 1-27. Vlg Forschungsvereinigung Kalk-Sand e.V. Hannover.

[20] Mörtel, H. (1980) Mineralbestand, Gefüge und physikalische Eigenschaften von Kalksandsteinen. Fortschritte der Mineralogie, 58, 37-67.

[21] Hamid, S.R. (1981) The Crystal Structure of the $11 \AA$ Natural Tobermorite $\mathrm{Ca}_{2.25}\left[\mathrm{Si}_{3} \mathrm{O}_{7.5}(\mathrm{OH})_{1.5}\right] \cdot 1 \mathrm{H}_{2} \mathrm{O}$. Zeitschrift für Kristallographie, 154, 189-198. http://dx.doi.org/10.1524/zkri.1981.154.3-4.189

[22] Merlino, S., Bonaccorsi, E. and Armbruster, T. (1999) Tobermorites: Their Real Structure and Order-Disorder (OD) Character. American Mineralogist, 84, 1613-1621.

[23] Merlino, S., Bonaccorsi, E. and Armbruster, T. (2001) The Real Structure of Tobermorite 11A: Normal and Anomalous Forms, OD Character and Polytypic Modifications. European Journal of Mineralogy, 13, 577-590. http://dx.doi.org/10.1127/0935-1221/2001/0013-0577

[24] Kendel, F. (1978) Dampfhärtung von Kalksandstein bei verlängerter Härtezeit und niedrigen Temperaturen: Einfluss auf die Steineigenschaften. Schriftenreihe Forschungsvereinigung Kalk-Sand e.V. Hannover, Nr. 46, 1-49.

[25] Hartmann, A. and Buhl, J.-Ch. (2010) The Influence of Sucrose on the Crystallization Behaviour in the System $\mathrm{CaO}-\mathrm{SiO}_{2}-\mathrm{C}_{12} \mathrm{H}_{22} \mathrm{O}_{11}-\mathrm{H}_{2} \mathrm{O}$ under Hydrothermal Conditions. Materials Research Bulletin, 45, 396-402. http://dx.doi.org/10.1016/j.materresbull.2009.12.033

[26] Hartmann, A., Khakhutov, M. and Buhl, J.-Ch. (2014) Hydrothermal Synthesis of CSH-Phases (Tobermorite) under Influence of Ca-Formate. Materials Research Bulletin, 51, 389-396. http://dx.doi.org/10.1016/j.materresbull.2013.12.030

[27] Hartmann, A., Schulenberg, D. and Buhl, J.-Ch. (2013) Untersuchung der Übergangsreaktion von Tobermorit zu 
Xonotlit unter dem Einfluss von Additiven und erhöhter Temperatur. Z. Krist. Suppl., No. 33, MS13-T04, 40-41.

[28] Hartmann, A., Buhl, J.-Ch. and van Breugel, K. (2007) Structure and Phase Investigations on Crystallization of $11 \AA$ Tobermorite in Lime Sand Pellets. Cement and Concrete Research, 37, 21-31. http://dx.doi.org/10.1016/j.cemconres.2006.09.007

[29] International Centre for Diffraction Data, 12 Campus Boulevard, Newton Square, Pennsylvania 19073-3273, USA.

[30] Yu, P., Kirkpatrick, R.J., Poe, B., McMillan, P.F. and Cong, X. (1999) Structure of Calcium Silicate Hydrate (C-S-H): Near-, Mid-, and Farinfrared Spectroscopy. Journal of the American Ceramic Society, 82, 742-748.

[31] Günzler, H. and Grünlich, H.-U. (2003) IR Spectroscopy: An Introduction. Wiley-VCH, Weinheim.

[32] Rickert, J. (2004) Influence of Retarders on the Hydration of Clinker and Cement, Part II. Concrete Technology Reports 2001-2003. Verlag Bau + Technik GmbH, Düsseldorf. 